\title{
Recommendation for laparoscopic ultrasound guided laparoscopic left lateral transabdominal adrenalectomy
}

\author{
Maciej Sebastian, Jerzy Rudnicki \\ Department of General, Minimally Invasive and Endocrine Surgery, Wroclaw Medical University, Wroclaw, Poland \\ Contributions: (I) Conception and design: All authors; (II) Administrative support: All authors; (III) Provision of study materials or patients: All \\ authors; (IV) Collection and assembly of data: All authors; (V) Data analysis and interpretation: All authors; (VI) Manuscript writing: All authors; \\ (VII) Final approval of manuscript: All authors. \\ Correspondence to: Maciej Sebastian, MD, PhD. Department of General, Minimally Invasive and Endocrine Surgery, Wroclaw Medical University, \\ Borowska Street 213, Wroclaw, Poland. Email: mseba@op.pl.
}

\begin{abstract}
Background Left sided adrenalectomy may be associated with intraoperative bleeding and conversion or injury of the pancreatic tail leading to postoperative fistula. Another problem may be the identification of adrenal mass in the case of previous upper abdominal surgery. Intraoperative laparoscopic ultrasound (LUS) enables the safe plane of dissection, identification of key structures and reduction of conversion and complication rate to the minimum.

Methods: Laparoscopic left lateral transabdominal adrenalectomy (LTA) was performed in 94 patients. LUS was performed in 50 patients with identification of adrenal mass, its vascularization and surrounding anatomical planes.

Results: Laparoscopic left LTA with LUS was associated with significant shorter operating time, smaller rate of conversions and intraoperative bleeding in comparison to the group without intraoperative ultrasound.

Conclusions: Intraoperative ultrasound during laparoscopic left LTA is a very effective method of navigation and its use should be taken into consideration especially in cases when the visualization and possibility of safe dissection are reduced.
\end{abstract}

Keywords: Ultrasound; laparoscopic surgery; adrenalectomy

Submitted Dec 15, 2019. Accepted for publication Mar 06, 2020.

doi: 10.21037 /gs.2020.03.35

View this article at: http://dx.doi.org/10.21037/gs.2020.03.35

\section{Introduction}

Laparoscopic adrenalectomy was first performed by Gagner et al. in 1992 and is nowadays a general accepted method of adrenalectomy for almost all indications in adrenal surgery (1-3). Three minimally invasive approaches are now available: the conventional laparoscopic, posterior retroperitoneoscopic and robotic assisted (4). The retroperitoneoscopic adrenalectomy is associated with the shortest hospital stay and robotic adrenalectomy is only cost effective in high volume centers (4). In general, minimally invasive approach offers several advantages over open surgery, such as earlier recovery, smaller incisions with decreased rate of incisional hernias, decreased postoperative pain, shorter length of hospital stay and lower blood loss with equivalent complications rates (4-6). Open adrenalectomy is recommended when adrenocortical carcinoma is suspected preoperatively or in case of very large tumors $(4,7,8)$. Left sided procedure may be associated with problematic identification of the adrenal gland or injury of the pancreatic tail thus additional intraoperative visualization may be very helpful $(9,10)$. Laparoscopic ultrasound (LUS) as a safe method of visualization seems to be an ideal adjunct to a complication free outcome (10).

\section{Methods}

The study group consisted of 94 patients (50 women and 44 men) operated on between January 2012 and December 


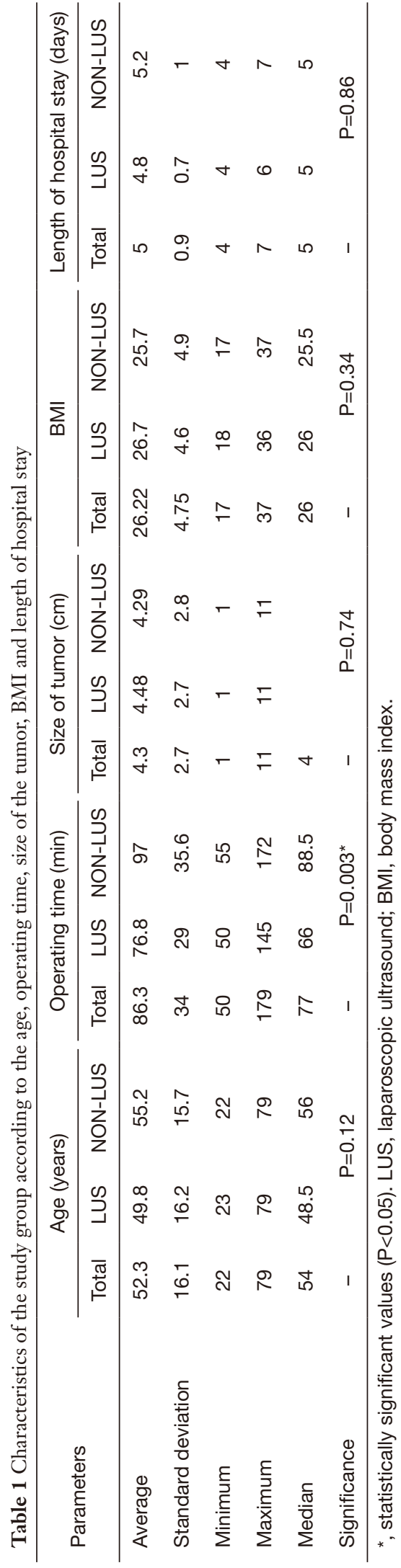

2018 in one center for endocrine surgery. The patients were qualified for adrenalectomy due to hormonally active tumors $(55 \%)$ or non-functioning adrenal tumors (45\%). Inclusion criterium for the study was the indication for adrenalectomy due to reasons mentioned above and laparoscopic left lateral transabdominal adrenalectomy (LTA). Exclusion criterium was the pre- or postoperatively diagnosed cancer of the adrenal gland and other operative procedures than LTA (not conversion). LTA with LUS was performed in 50 patients, LTA without LUS in 44 patients. Operations with LUS started in January 2015 and since then all patients were operated under LUS guidance. All the procedures were performed by two experienced endocrine surgeons. Written informed consent was obtained from all patients before surgery. All procedures were in accordance with the ethical standards of the 1964 Declaration of Helsinki and its later amendments. The study was approved by an Institutional Review Board of Wroclaw Medical University (ID BW-24/2020). Characteristics of the study group are presented in Tables 1,2.

We used the laparoscopic probe Toshiba PEF-704 LA (frequency 7.0 MHz) for LUS and the diagnostic ultrasound system Toshiba NemioMX SSA-590A all manufactured in Japan. LUS was performed routinely in every patient in LUS group. LUS probe was inserted through the $10 \mathrm{~mm}$ trocar. Vascular and avascular structures were differentiated with duplex doppler function. LUS was performed before, during and after preparation in the operative area. A sodium chloride isotonic solution was used to improve acoustic coupling between the probe and the scanned surface. When the intraoperative conditions were difficult (e.g., adhesions, changed anatomy) there was an attempt to find the correct plane of dissection with LUS (Video 1) (Figure 1A,B,C). When the safe preparation was impossible or when the bleeding could not be controlled laparoscopically the operation was converted. After removal of the adrenal gland the drain was left in place to diagnose postoperative bleeding or postoperative pancreatic fistula. LUS was used to localize the adrenal gland and its vascularization and to find the correct plane of dissection (Figure 1D,E,F). Statistical analysis included the unpaired $t$-test for continuous and Fisher's exact test for binary variables. The level of statistical significance was set at $95 \%(\mathrm{P}<0.05)$.

\section{Results}

Conversions were performed in 1 (2\%) patient in LTA with LUS group and in $6(13.6 \%)$ patients in LTA without 


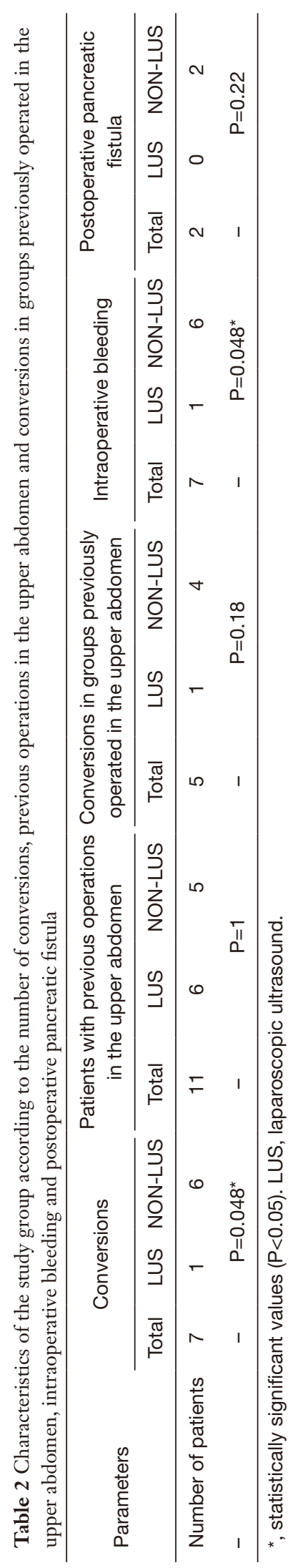

LUS group. In LUS group we observed 1 (2\%) case of intraoperative bleeding and no postoperative pancreatic fistula. In group without LUS there were $6(13.6 \%)$ cases of intraoperative bleeding from adrenal vessels and 2 (4.5\%) cases of postoperative pancreatic fistula. The reason of conversion in the LUS group were very dense adhesions, in the group without LUS 2 (4.5\%) cases of massive bleeding from adrenal vessels and 4 (9\%) cases of dense adhesions making the correct identification of adrenal gland, its vascularization and pancreatic tail impossible (difficult anatomy). The mean time of operation was significantly shorter, conversion and intraoperative bleeding rate significantly smaller in the LUS group in comparison to the group without LUS. We did not observed any significant differences in the age, size of the tumor, body mass index (BMI) and length of hospital stay between the study groups. The previous upper abdominal surgery was observed in $6(12 \%)$ patients from the LUS group and in $5(11.4 \%)$ patients in the group without LUS and the number of conversions in previously operated patients between these two groups of patients was not statistically significant. The results are presented in Tables 1,2.

\section{Discussion}

Laparoscopic approach to the adrenal glands usually enables a very precise, minimally invasive and hemostatic dissection with complication rates not different from an open approach $(4-6,11,12)$. Left sided procedure is featured by the lack of major anatomic landmarks, blood vessels located in the retroperitoneal fat and the proximity of the pancreatic tail (13). The prerequisites for successful adrenalectomy are thorough knowledge of retroperitoneal anatomy, precise dissection and hemostasis and gentle tissue handling enabling complication free surgery (14-16). Previous abdominal or retroperitoneal surgery may be associated with adhesions and difficult anatomy leading to intraoperative bleeding, damage of surrounding organs (spleen, pancreas) and problems with localization of the adrenal gland. LTA on the left side may be typical associated with injuries to the pancreatic tail or hemorrhage from the retroperitoneal adrenal vessels or the splenic vasculature (9). The rate of distal pancreatic injuries varies between $2.5-8.6 \%$ for left sided procedure what may lead to the postoperative pancreatitis and/or fistula $(9,17)$. The rate of conversions varies between $0-13 \%$ due to extensive adhesions, hemorrhage, difficult dissection, organ injury and iatrogenic pneumothorax $(9,18-28)$. According to 

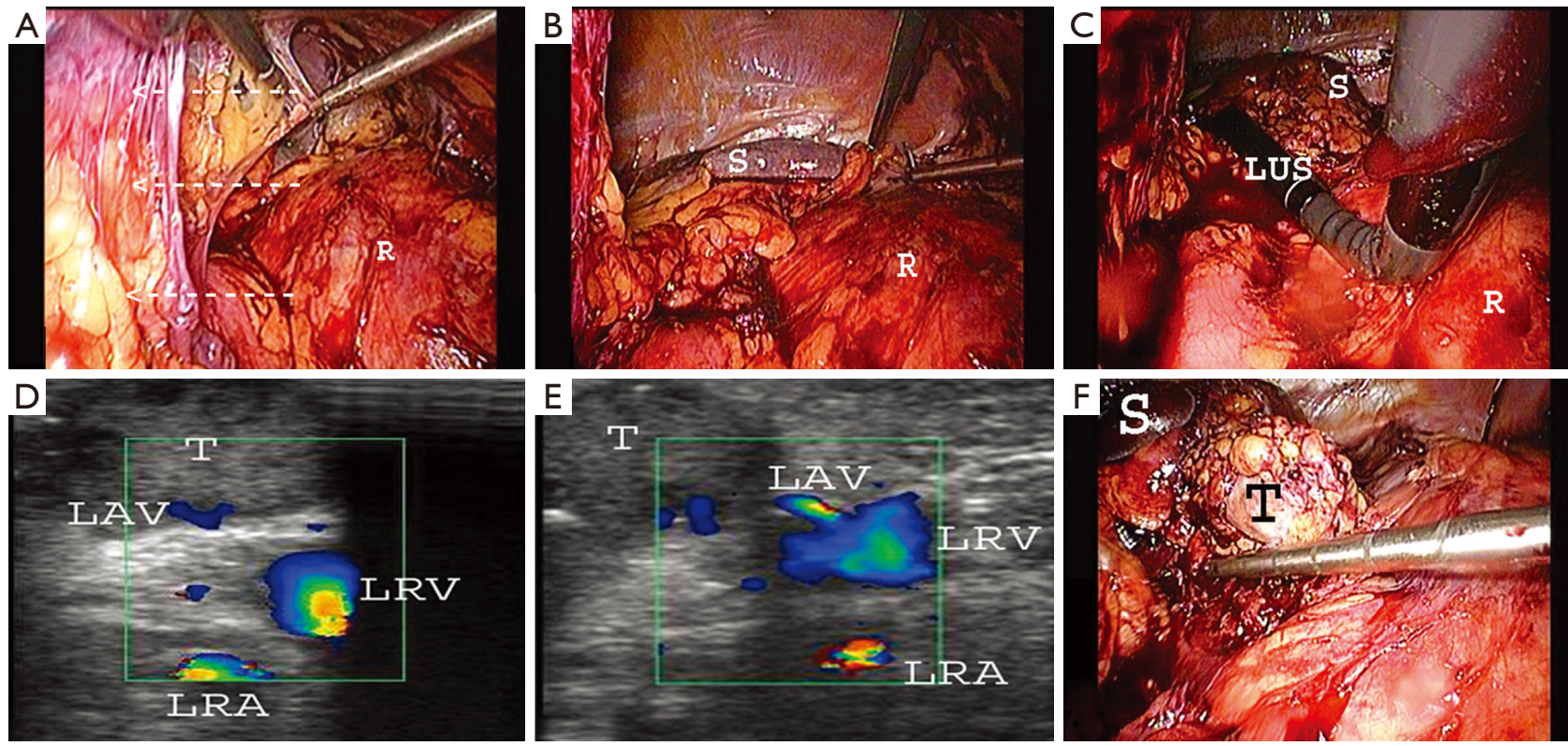

Figure 1 The following steps of LUS guided left LTA in case of adhesions (white arrows) and changed anatomy. (A) Removal of adhesions; (B) after removal of adhesions the retroperitoneal space is well visible; (C) LUS is used to localize the tumor in the left adrenal gland and its vascularization and define the right plane of dissection; (D,E) the tumor in the left adrenal gland and its vascularization were found with LUS; (F) after precise localization the left adrenal gland with tumor was removed in a safe way without intraoperative complications. LTA, lateral transabdominal adrenalectomy; LAV, left adrenal vein; LRA, left renal artery; LRV, left renal vein; LUS, laparoscopic ultrasound; R, retroperitoneum; S, spleen; T, tumor.

our observations LUS significantly reduces the operating time and conversion rate-the independent risk factor for complications is conversion to open surgery and adrenalectomy on the left side what is associated with the partial mobilization of the left pancreas and spleen (29). LUS may be very helpful in exact localization of the adrenal gland and its vascularization resulting in precise, directed, time efficient and bloodless dissection (10). In case of a close proximity of the pancreatic tail LUS enables to find the correct plane of dissection. LUS is extremely useful in patients after previous upper abdominal surgery when the anatomical planes may be changed but some authors do not find any significant association between previous surgery and conversion rate and we also did not find such significant correlation (1,30). LUS is non-invasive and non-irradiating, can be performed before, during and after dissection and repeated as many times as needed without negative impact on the patient and operating staff (31). The limitations of our study are the relative small study groups and the data only from one endocrine surgery center thus further studies on bigger groups of patients are needed what might lead to a more common usage of LUS in adrenal surgery.

\section{Acknowledgments}

Funding: None.

\section{Footnote}

Conflicts of Interest: Both authors have completed the ICMJE uniform disclosure form (available at http://dx.doi. org/10.21037/gs.2020.03.35). The authors have no conflicts of interest to declare.

Ethical Statement: The authors are accountable for all aspects of the work in ensuring that questions related to the accuracy or integrity of any part of the work are appropriately investigated and resolved. The study was approved by an Institutional Review Board of Wroclaw Medical University (ID BW-24/2020). Written informed consent was obtained from all patients before surgery. All procedures were in accordance with the ethical standards of the 1964 Declaration of Helsinki and its later amendments.

Open Access Statement: This is an Open Access article 
distributed in accordance with the Creative Commons Attribution-NonCommercial-NoDerivs 4.0 International License (CC BY-NC-ND 4.0), which permits the noncommercial replication and distribution of the article with the strict proviso that no changes or edits are made and the original work is properly cited (including links to both the formal publication through the relevant DOI and the license). See: https://creativecommons.org/licenses/by-nc-nd/4.0/.

\section{References}

1. Mazeh H, Froyshteter AB, Wang TS, et al. Is previous same quadrant surgery a contraindication to laparoscopic adrenalectomy? Surgery 2012;152:1211-7.

2. Gagner M, Lacroix A, Bolté E. Laparoscopic adrenalectomy in Cushing's syndrome and pheochromocytoma. N Engl J Med 1992;327:1033.

3. Melman L, Matthews BD. Current trends in laparoscopic solid organ surgery: spleen, adrenal, pancreas, and liver. Surg Clin North Am 2008;88:1033-46, vii.

4. Heger P, Probst P, Hüttner FJ, et al. Evaluation of open and minimally invasive adrenalectomy: a systematic review and network meta-analysis. World J Surg 2017;41:2746-57.

5. Zografos GN, Farfaras A, Vasiliadis G, et al. Laparoscopic resection of large adrenal tumors. JSLS 2010;14:364-8.

6. Gumbs AA, Gagner M. Laparoscopic adrenalectomy. Best Pract Res Clin Endocrinol Metab 2006;20:483-99.

7. Ramacciato G, Mercantini P, La Torre M, et al. Is laparoscopic adrenalectomy safe and effective for adrenal masses larger than 7 cm? Surg Endosc 2008;22:516-21.

8. Gonzalez RJ, Shapiro S, Sarlis N, et al. Laparoscopic resection of adrenal cortical carcinoma: a cautionary note. Surgery 2005;138:1078-85; discussion 1085-6.

9. Kokorak L, Soltes M, Vladovic P, et al. Laparoscopic left and right adrenalectomy from an anterior approach - is there any difference? Outcomes in 176 consecutive patients. Wideochir Inne Tech Maloinwazyjne 2016;11:268-73.

10. Brunt LM, Bennett HF, Teefey SA, et al. Laparoscopic ultrasound imaging of adrenal tumors during laparoscopic adrenalectomy. Am J Surg 1999;178:490-5.

11. Lev-Chelouche D, Sagie B, Keidar A, et al. Laparoscopic adrenalectomy: indications, technique, complications and follow-up. Isr Med Assoc J 2003;5:101-4.

12. Raeburn CD, McIntyre RC Jr. Laparoscopic approach to adrenal and endocrine pancreatic tumors. Surg Clin North Am 2000;80:1427-41.

13. Raffaelli M, De Crea C, Bellantone R. Laparoscopic adrenalectomy. Gland Surg 2019;8:S41-52.

14. Gagner M, Lacroix A, Bolte E, et al. Laparoscopic adrenalectomy. The importance of a flank approach in the lateral decubitus position. Surg Endosc 1994;8:135-8.

15. Marescaux J, Mutter D, Wheeler MH. Laparoscopic right and left adrenalectomies. Surgical procedures. Surg Endosc 1996;10:912-5.

16. Henry JF. Minimally invasive adrenal surgery. Best Pract Res Clin Endocrinol Metab 2001;15:149-60.

17. Varkarakis IM, Allaf ME, Bhayani SB, et al. Pancreatic injuries during laparoscopic urologic surgery. Urology 2004;64:1089-93.

18. Paganini AM, Balla A, Guerrieri M, et al. Laparoscopic transperitoneal anterior adrenalectomy in pheochromocytoma: experience in 62 patients. Surg Endosc 2014;28:2683-9.

19. Pillinger SH, Bambach CP, Sidhu S. Laparoscopic adrenalectomy: a 6-year experience of 59 cases. ANZ J Surg 2002;72:467-70.

20. Henry JF, Defechereux T, Raffaelli M, et al. Complications of laparoscopic adrenalectomy: results of 169 consecutive procedures. World J Surg 2000;24:1342-6.

21. Assalia A, Gagner M. Laparoscopic adrenalectomy. Br J Surg 2004;91:1259-74.

22. Economopoulos KP, Phitayakorn R, Lubitz CC, et al. Should specific patient clinical characteristics discourage adrenal surgeons from performing laparoscopic transperitoneal adrenalectomy? Surgery 2016;159:240-8.

23. Park HS, Roman SA, Sosa JA. Outcomes from 3144 adrenalectomies in the United States: which matters more, surgeon volume or specialty? Arch Surg 2009;144:1060-7.

24. Hauch A, Al-Qurayshi Z, Kandil E. Factors associated with higher risk of complications after adrenal surgery. Ann Surg Oncol 2015;22:103-10.

25. Palazzo F, Dickinson A, Phillips B, et al. Adrenal surgery in England: better outcomes in high-volume practices. Clin Endocrinol (Oxf) 2016;85:17-20.

26. Bittner JG 4th, Gershuni VM, Matthews BD, et al. Risk factors affecting operative approach, conversion, and morbidity for adrenalectomy: a single-institution series of 402 patients. Surg Endosc 2013;27:2342-50.

27. Thompson LH, Nordenström E, Almquist M, et al. Risk factors for complications after adrenalectomy: results from a comprehensive national database. Langenbecks Arch Surg 2017;402:315-22.

28. Chen Y, Scholten A, Chomsky-Higgins K, et al. Risk factors associated with perioperative complications and prolonged length of stay after laparoscopic adrenalectomy. JAMA Surg 2018;153:1036-41.

29. Gaujoux S, Bonnet S, Leconte M, et al. Risk factors for 
conversion and complications after unilateral laparoscopic adrenalectomy. Br J Surg 2011;98:1392-9.

30. Toutounchi S, Pogorzelski R, Legocka ME, et al. Lateral laparoscopic adrenalectomy in patients with previous abdominal surgery - single-center experience. Wideochir
Inne Tech Maloinwazyjne 2018;13:283-7.

31. Dili A, Bertrand C. Laparoscopic ultrasonography as an alternative to intraoperative cholangiography during laparoscopic cholecystectomy. World J Gastroenterol 2017;23:5438-50.
Cite this article as: Sebastian M, Rudnicki J. Recommendation for laparoscopic ultrasound guided laparoscopic left lateral transabdominal adrenalectomy. Gland Surg 2020;9(3):689-694. doi: 10.21037 /gs.2020.03.35 